\begin{tabular}{cc}
\hline & International Journal of Engineering \& Technology, $7(3.20)(2018) 339-343$ \\
SPC & International Journal of Engineering \& Technology \\
Website: ww.sciencepubco.com/index.php/IJET & Research paper \\
\hline
\end{tabular}

\title{
Data Envelopment Analysis (Dea) Approach In Efficiency Transport Manufacturing Industry in Malaysia
}

\author{
${ }^{1}$ Mohd Fahmy-Abdullah, ${ }^{2}$ Basri Abdul Talib \\ ${ }^{1}$ Faculty of Technology Management and Business, Universiti Tun Hussien Onn Malaysia \\ ${ }^{2}$ Faculty of Economics and Management, Universiti Kebangsaan Malaysia \\ Corresponding Author Email: mohdfahmy@uthm.edu.my
}

\begin{abstract}
The objective of this study was to measure of technical efficiency, transport manufacturing industry in Malaysia score using the data envelopment analysis (DEA) from 2005 to 2010. The efficiency score analysis used only two inputs, i.e., capital and labor and one output i.e., total of sales. The results shown that the average efficiency score of the Banker, Charnes, Cooper - Variable Returns to Scale (BCCVRS) model is higher than the Charnes, Cooper, Rhodes - Constant Return to Scale (CCR-CRS) model. Based on the BCC-VRS model, the average efficiency score was at a moderate level and only four sub-industry that recorded an average efficiency score more than 0.50 percent during the period study. The implication of this result suggests that the transport manufacturing industry needs to increase investment, especially in human capital such as employee training, increase communication expenses such as ICT and carry out joint ventures as well as research and development activities to enhance industry efficiency.
\end{abstract}

Keyword: Data Envelopment Analysis, technical efficiency, transportation, manufacturing, industry

\section{Introduction}

The challenges of trade liberalization policies such as the ASEAN Free Trade Area (AFTA) and the removal of trade barriers between ASEAN countries, the development of transport manufacturing industry are still volatile ([15]; [21]). In fact, the implementation of the Commonwealth Preferential Tariff (CEPT) scheme and promotional activities of various regional integration schemes within the AFTA area further increased the pressure to liberalize the transport manufacturing industry in the ASEAN region [17]. As a result, the contribution of the transport manufacturing industry to the Gross Domestic Product (GDP) declined in 2010 (2.4 per cent) compared to 2005 (3.0 per cent) [3]. While the trade performance showed a deficit growth with an increase in total imports of RM 21.7 billion and higher than exports, which recorded only RM 5.3 billion in 2010 . The capitallabor ratio decreased from 119.5 per cent in 2005 to 97.27 per cent in 2010 .

This situation has resulted in an average annual growth of -4.0 per cent ([21]; NAP, 2014). Overall, the current performance of the transport manufacturing industry shows that Malaysia ranks only 29th out of 155 countries. Liberalization has demanded additional output capacity by using existing inputs in the transport manufacturing industry (Malaysia Productivity Corporation 2012/2013). This situation demonstrates that efficiency must be high to address the emergence of new operations, changes in technological efficiency and new technologies that ultimately seek to improve the momentum of the country's economic growth. The openness of economic and liberalization resulted in the country's economic growth momentum could not be improved if the industry was not ready to improve the efficiency ([18]; [1]). In facts, liberalization has demanded the capacity of the transport manufacturing industry to increase the amount of additional output or value added using the existing firm's input to produce optimum output (Malaysia Productivity Corporation 2012/2013).

The efficiency is effectively effective input users influenced by production techniques, technological innovation, management skills and labor skills. While the technical efficiency illustrates that the firm's ability to produce maximum output when supplied with a set of inputs [14]. The optimum combination of input and output usage can produce output capable of contributing to increased productivity. In recent years, the measure of efficiency has shown significant progress in relation to productive activities. The non-parametric approach (DEA) is among the major approaches used to measure technical efficiency [16]. This approach is a popular and frequently used method for measuring the efficiency of a firm or industry [19] and it's also an alternative approach that has been widely studied as a multi-industry or organizational methodology [10]. [14] introduced the DEA method that estimates the relationship between inputs and outputs with the minimum assumptions and is able to measure Decision Making Unit (DMU) that's to be efficient and sensitive to unreliable data [5]. [4] mention that efficient DMUs will form the boundary of efficiency for all other units under the boundary. The DEA method does not allow random errors as well as hypothesis testing and statistics are not conducted to estimate the efficiency score [4] .

The study of efficiency that related to the transportation industry have grown rapidly in recent times, including [27], [2] and [26]. In Malaysia, studies on the technical efficiency of transportation, manufacturing firms receive less attention compared to the studies on the firms in other industries. Previous studies have discussed transportation, manufacturing firms in general and as a part of studies on the manufacturing industry. Only a few studies focused on the efficiency study of the transport manufacturing industry such as Idris and Jajri (2008) which showed a change in efficiency 
and productivity, while [17] compared the efficiency of local ownership and foreign ownership. In addition, [13] has examined the efficiency using parametric methods.

The contribution of this paper to the transport manufacturing industry should be taken seriously. This paper is a comprehensive analysis that measures the level of technical efficiency of the transport manufacturing industry from 2005 to 2010 . It aims to fill the existing research gap as the industry receives less attention compared to the studies on the firms in other industries. This study is important to determine the basic implications that need to be done to address the challenges of liberalization. The structure of this article is divided into several sections; the second section of this paper discusses the methodology of the study and the selection of inputs and output. The third section analyses the results of the survey and the fourth section provides the conclusions and the implications of this study.

\section{Methodology and Data}

Data Envelopment Analysis (DEA). The DEA method founded by [14] is a non-parametric linear programming technique to aim the assessing of firms or organization's performance (i.e., DMU in the DEA literature). [7] and [8] have carried out further studies to measure the efficiency level and propose an input-oriented model, i.e., Charnes, Cooper and Rhodes Model (CCR Model). This approach measure that input reduction or output increase at a constant rate (constant return to scale - CRS) for each DMUs or also known as the CCR-CRS model that provides General Technical Efficiency (GTE) scores [23].

The CCR model with the assumption of CRS can be formulated as follows;

$\min l_{\mathrm{o}}{ }^{*}-$

subject to:

$$
\begin{array}{cc}
\varepsilon\left(\sum_{j=1}^{m} S_{i}^{-}+\sum_{r=1}^{s} S_{r}^{+}\right) & \\
\sum_{=1}^{N} \lambda_{f} x_{i f}=l_{0} \mathrm{x}_{i f o}-S_{i}^{-} & \text {where } i=1 \ldots m \\
\sum_{f=1}^{N} \lambda_{f} y_{r f}=S_{r}^{+}-\mathrm{y}_{r f o} & \text { where } r=1 \ldots s \\
\lambda_{f} \geq 0, f=1 \ldots N, S_{i}^{-}, S_{r}^{+} \geq 0 \square \square i \text { and } r &
\end{array}
$$

where $x_{i f}$ and $y_{r f}$ are levels of the $i$ th input and $r$ th output respectively, for DMU $f$; $\mathrm{N}$ is the number of DMUs; $\varepsilon$ is a very small positive number (non-Archimedean) used as a lower bound to inputs and outputs; $\lambda_{f}$ denotes the contribution of DMU $f$ in deriving the efficiency of the rated DMU $f_{o}$ (a point at the envelopment surface); $S_{r}^{+}$and $S_{r}^{-}$are slack varibales to proxy extra savings in input $i$ and extra gains in output $r ; l_{\mathrm{o}}$ is the radial efficiency factor that shows the possible reduction of inputs for DMU $f_{o}$. If $l_{0}{ }^{*}$ (optimal solution) is equal to one and the slack values are both equal to zero, then $\mathrm{DMU} f_{o}$ is said to be efficient When $S_{r}^{+}$dan $S_{r}^{-}$take positive values at the optimal solution, one can conclude that the corresponding input or output of DMU $f_{o}$ can improve further once input levels have been contracted to the proportion $l_{0}{ }^{*}$.

The CCR model presupposes that there is no significant relationship between the scale of operations and efficiency by assuming CRS and it delivers the overall TE. The CRS assumption is only justifiable when all DMUs are operating at an optimal scale. However, banks in practice may face either economies or diseconomies of scale. Thus, if one makes the CRS assumption when not all DMUs are operating at the optimal scale, the computed measures of TE will be contaminated with SE.

[5] extended the CCR model by relaxing the CRS assumption. The resulting Banker, Charnes and Cooper (BCC) model is used to assess the efficiency of DMUs characterized by variable returns to scale (VRS). The VRS assumption provides the measurement of pure technical efficiency (PTE), which is the measurement of TE devoid of the SE effects. If there appears to be a difference between the TE and PTE scores of a particular DMU, then it indicates the existence of scale inefficiency, i.e., TE $=$ PTE $x$ SE. The former relates to the capability of managers to utilize bank's given resources, whereas the latter refers to exploiting scale economies by operating at a point where the production frontier exhibits CRS.

The input-oriented BCC model with VRS assumption can be represented by the following linear programming problem;

$\min l_{\mathrm{o}}^{*}-$

$$
\begin{aligned}
\varepsilon\left(\sum_{j=1}^{m} S_{i}^{-*}+\sum_{r=1}^{S} S_{r}^{+*}\right) \\
\sum_{=1}^{N} \lambda_{f} x_{i f}=l_{0} \mathrm{x}_{i f o}-S_{i}^{-*} \\
\sum_{f=1}^{N} \lambda_{f} y_{r f}=S_{r}^{+*}-\mathrm{y}_{r f o}
\end{aligned}
$$$$
\text { where } \quad i=1 \ldots m
$$

subject to:$$
\lambda_{f} \geq 0, f=1 \ldots N, S_{i}^{-*}, S_{r}^{+*} \geq 0 \square \square i \text { dan } r
$$

The BCC model differs from the CCR model in that it includes the so-called convexity constraint, $\quad \lambda_{f}=1$, which prevents any interpolation point constructed from the observed DMUs from being scaled up or down to form a referent point. In this model, the set of $\lambda$ values minimize $l_{0}$ to $l_{0}{ }^{*}$ and identify a point within the VRS assumption, of which the input levels reflects the lowest proportion of $l_{0}{ }^{*}$. At $l_{0}{ }^{*}$, the input levels of DMU $f_{o}$ can be uniformly contracted without detriment its output levels. Therefore, DMU $f_{o}$ has efficiency equal to $l_{0}{ }^{*}$. The solution to model (2) is summarized in the following fashion: DMU $f_{o}$ is pareto-efficient if $l_{\mathrm{o}}{ }^{*}=1$ and $S_{r}^{+}=0, r=1 \ldots s, S_{r}^{-}=0, i=1 \ldots m$.
If the convexity constraints in model $\stackrel{N}{f}_{1}^{N}$ ) is dropped, one obtains model (1), which generates TE under the CRS assumption. This implies that PTE of a DMU is always greater or equal to its TE. Under the VRS assumption, the resulting SE can be measured, since in most cases, the scale of operation of the firm may not be optimal. The firm involved may be too small in its scale of operation, which might fall within the increasing CRS part of the production function. Similarly, a firm may be too large and operate within the decreasing returns to scale (DRS) part of the production function. In both cases, efficiency of the firms may be improved by changing their scale of operation. If the underlying 
production technology follows CRS, then the firm is automatically scale efficient. The resulting ratio illustrates SE, which is the impact of scale size on the efficiency of a DMU. Formally, the SE of DMU $f_{o}$ is given as TE/PTE. Where, TE and PTE are technical efficiency and pure technical efficiency of DMU $f_{o}$ respectively.

Since PTE is always greater or equal to TE, is means that SE (TE/PTE) is less or equal to unity. If TE and PTE of a DMU are equal, then $\mathrm{SE}$ is equal to one. This means that irrespective of scale, size has no impact on efficiency. If the TE scores derived from the CRS assumption is less than the TE scores derived from the VRS assumption, then SE will be below unity, meaning that the scale of operation does impact the efficiency of the DMU.

Specifications of Data. Based on $[20]^{1}$, this study uses three inputs i.e., capital, which is the value of purchase and fixed assets for construction and improvement during the reference year (measured in Ringgit Malaysia); employees, where they are all employees to earn wages and profits as employers or employees. While the intermediate input is also included in the input as a production factor which is the value of the materials and supplies used including the cost of industrial, utilities, the value of the combustion, lubricants and gas used and so on. Whereas total sales as a output, refers to the sale of a product manufactured by the firm (measured in Ringgit Malaysia). These variables descriptive can be seen in Table 1.

Table 1 Summary of Variables Descriptive $(2005-2010)$

\begin{tabular}{|c|c|c|c|c|}
\hline Variable & Mean & Minimum & Maximum & $\begin{array}{c}\text { Standard } \\
\text { Deviation }\end{array}$ \\
\hline Output & & & & \\
\hline $\begin{array}{c}\text { Total Sales } \\
\text { ('000) }\end{array}$ & 4176086 & 275896 & 21318011 & 4589477.059 \\
\hline Input & & & & \\
\hline Capital ('000) & 942623 & 57964 & 4465787 & 919913.636 \\
\hline $\begin{array}{c}\text { Total of } \\
\text { Workers }\end{array}$ & 8508 & 894 & 22477 & 6679.767 \\
\hline $\begin{array}{c}\text { Intermediate } \\
\text { Input ('000) }\end{array}$ & 4058439 & 201730 & 18044586 & 3944969.305 \\
\hline
\end{tabular}

Source: Department of Statistic, Malaysia, 2005 - 2010The study used data collected at the firm's level of the manufacturing industries which is controlled by the Department of Statistics (DOS). This data includes data in 2010 and in which the firms can be categorised into six sub-sectors on the 3-digit level by Malaysia Standard Industrial Classification (MSIC 2008). The data consists of manufacturing of motor vehicles, passenger cars and commercial vehicles; manufacturing of template (coachwork) for motor vehicles and manufacturing of trailers and semi-trailers; manufacturing of parts and accessories for motor vehicles; ship and boat building, shipbuilding and floating structures and construction of leisure boats and sports; construction of air and spacecraft and related machinery; transportation equipment manufacturing activities not elsewhere classified, manufacturing of motorcycles and bicycles and invalid carriages.

Based on the obtained data, 611 transportation manufacturing firms were involved in this study, and the number of firms were different each year. As a common practice in DEA studies, these variables had been mean-corrected prior to estimation. Besides that, all monetary variables are expressed in real 2005 Malaysian Ringgit.

\section{Result and Discussion}

This section discusses the results of technical efficiency scores, measured using DEAP software version 2.1 [8]. First, the efficiency decision was selected based on the CCR-CRS model with the BCC-VRS model. The second part shows the efficiency score obtained either as a whole or according to the manufacturing sub-industry during the period of study.

Analysis of Efficiency Score. Based on the CCR-CRS model and BCC-VRS model, the DEAP version 2.1 software [8] has been used to obtain the efficiency of the transport manufacturing industry. Table 2 shows the efficiency score of the CCR-CRS model and the BCC-VRS model from 2005 to 2010.

Table 2 CCR-CRS Model and BCC-VRS Model Efficiency Score

\begin{tabular}{|c|c|c|c|c|c|c|}
\hline & \multicolumn{7}{|c|}{ CCR-CRS Model } \\
\hline & 2005 & 2006 & 2007 & 2008 & 2009 & 2010 \\
\hline Mean & 0.266 & 0.396 & 0.364 & 0.363 & 0.347 & 0.213 \\
\hline & \multicolumn{7}{|c|}{ BCC-VRS Model } \\
\hline Mean & 2005 & 2006 & 2007 & 2008 & 2009 & 2010 \\
\hline
\end{tabular}

The results shown that the average efficiency score of the CCRCRS model has a lower every each year compared to the BCCVRS model with overall average value of 0.33 percent and 0.53 percent respectively. This decision is not surprising because the CCR-CRS model assumes that the input reduction or output increase is at a constant rate, while the BCC-VRS model assumes that the input reduction or output increase is at an inconvenient rate as well as delivering Local Pure Technical Efficiency (LPTE) without detecting economic scale (SE). Therefore, this study has been chosen the BCC-VRS model for transport manufacturing industry.

Based on the results of the BCC-VRS model, firms that were operating at an efficiency range lower than 0.50 percent were only in 2005 and 2010. Meanwhile, the firms that were operating at an efficiency range higher than 0.50 were in 2006, 2007, 2008 and 2009. In 2006 to 2009 and there was an increase in efficiency score from 2006 to 2009. The increase was due to high demand as a result of encouraging economic growth of between 4 to 5 per cent per annum and increased purchasing power [21]. However, the efficiency score of the transport manufacturing industry has dropped significantly in 2010 at 0.45 percent compared to 0.56 percent in 2009. This is because of the international financial crisis impact which has resulted in severe fall in world trade due to the sharp decline in demand for exports from developing economies. As a result, exports and economic output recorded severe downturns [12]. As a result, firms have to reduce the costing includes reducing skilled labor, limiting to use of high technology and not investing heavily in raising employee's human capital such as providing training to employees. In fact, based on GDP National Income Accounts Report for the period 2005-2011, lower external demand and supply disruptions from European, Japanese and Thai countries have resulted in the manufacturing

industry experiencing a negative growth of one per cent in 2011 . Therefore, firms, especially those operating under the efficiency value range of 0.50 , should increase the efficiency value to produce optimum output or output.

Sub-industry Efficiency Result. Table 3 shows the results of technical efficiency scores according to the transportation manufacturing sub-sector in Malaysia from 2005 to 2010. Based on the table, the overall engineering efficiency score was at moderate level throughout period of the study. Subindustries 6, i.e., manufacturing of transport equipment which is not classified elsewhere, manufacturing of motorcycles and bicycle manufacturing and handicraft vehicles has recorded the highest efficiency score almost every year except in 2008 compared to other subindustries, i.e., 0.50 per cent, 0.57 per cent, 0.65 per cent, 0.71 per cent and 0.56 per cent. The number of establishments of 90 firms in 2010 has boosted the sub-industry in the market. In fact, the gross output contribution which grew by 10.8 per cent in 2010 indicates that most firms in this sub-industry have high efficiency scores [11] and [12]. 
In contrast, in 2008, saw the manufacturing sub-industry of 1, i.e. manufacturing of motor vehicles, passenger cars and manufacturing of commercial vehicles, recorded the highest efficiency score compared to other sub-industries of 0.72 percent. Based on statistical reports by the Department of Statistics Malaysia (DOS), this sub-industry has been emphasized since the transport industry has grown. In fact, high production volumes have pushed the efficiency of this sub-industry to increase during the year.

In 2009, it also recorded the highest efficiency score for the three sub-industries, namely sub-industries 3,4 and 6 , which were 0.59 per cent, 0.62 per cent and 0.71 per cent respectively. In 2006, the highest score for sub-industries 2 and 5 was 0.54 per cent respectively. As of 2008 , the sub-industry 1 had the highest efficiency score of 0.73 percent. The findings also found that subindustries 1 had the lowest efficiency score in 2005 and 2010. While sub-industries 2 had the lowest efficiency score in 2007 and 2008 at 0.50 percent and 0.40 percent. Additionally, the 4 and 5 sub-industries recorded the lowest efficiency score in 2006 and 2009 , which were 0.53 per cent and 0.39 per cent respectively.

Table 3 Efficiency Score of Transport Manufacturing Sub-industry, 2005 - 2010

\begin{tabular}{|c|c|c|c|c|c|c|}
\hline & \multicolumn{6}{|c|}{ BCC-VRS Model } \\
\hline & 2005 & 2006 & 2007 & 2008 & 2009 & 2010 \\
\hline 1 & 0.348 & 0.541 & 0.616 & 0.724 & 0.594 & 0.389 \\
\hline 2 & 0.480 & 0.536 & 0.497 & 0.398 & 0.475 & 0.440 \\
\hline 3 & 0.405 & 0.535 & 0.568 & 0.559 & 0.585 & 0.503 \\
\hline 4 & 0.480 & 0.525 & 0.610 & 0.575 & 0.615 & 0.411 \\
\hline 5 & 0.442 & 0.542 & 0.535 & 0.520 & 0.391 & 0.394 \\
\hline 6 & 0.504 & 0.574 & 0.651 & 0.675 & 0.705 & 0.557 \\
\hline Mean & 0.443 & 0.542 & 0.579 & 0.575 & 0.560 & 0.449 \\
\hline
\end{tabular}

Note: 1 = manufacturing of motor vehicles, passenger cars and commercial vehicles; 2 = manufacturing of template (coachwork) for motor vehicles and manufacturing of trailers and semi-trailers; 3 = manufacturing of parts and accessories for motor vehicles; $4=$ ship and boat building, shipbuilding and floating structures and construction of leisure boats and sports; $5=$ construction of air and spacecraft and related machinery; $6=$ transportation equipment manufacturing activities not elsewhere classified, manufacturing of motorcycles and bicycles and invalid carriages.

Overall, the sub-industries 1, 3, 4 and 6 recorded an overall efficiency score of 0.50 per cent, i.e., 0.53 per cent, 0.52 per cent, 0.54 per cent and 0.61 per cent respectively during the review period. On the other hand, sub-industries 2 and 5 recorded average overall efficiency score of less than 0.50 per cent, respectively, of 0.47 per cent respectively.

\section{Conclusions}

This study measures the technical efficiency score of the transport manufacturing industry in Malaysia from 2005 to 2010 Estimation of the efficiency score of the transport manufacturing industry is based on the DEA approach which consists of one input, i.e., sales and three outputs i.e., capital, employees and intermediate inputs. The results shown that the average efficiency score of the CCR-CRS model has a lower every each year compared to the BCC-VRS model. This decision is not surprising because the CCR-CRS model assumes that the input reduction or output increase is at a constant rate, while the BCC-VRS model assumes that the input reduction or output increase is at an inconvenient rate as well as delivering Local Pure Technical Efficiency (LPTE) without detecting economic scale (SE).

The results obtained in this study can be associated with some policy implications. Firstly, the investment in human capital such as training to employees is a long-term asset that can provide a positive return over the period of employee service with the firms. The training can provide skilled manpower as well as reduce dependency on skilled workers and thus help to create a highincome local skilled workforce. It's should be given to improving skills and capabilities such as leadership, management, engineering, quality, design, ICT and cost management even though employees do not have high levels of education. Firms can achieve optimal amounts of output if more efficient production operations are carried out by increasing in human capital. Therefore, continuous investments in human capital are very important, and the government's emphasis on this aspect should be continued.
Secondly, high technology production also needs to be in line with the efficiency level among employees, so that employees can adapt to new technologies. Therefore, the placement of experts in the industry should be undertaken to enhance the leadership skills, management and quality capabilities for human capital development among employees that ultimately increase the production and efficiency of the transport manufacturing industry. In addition, research and development activities need to be multiplied, including increasing expertise, providing appropriate green technology infrastructure and enhancing strategic collaboration between local firms with international firms and local universities. Additionally, strategic collaboration through collaborative programs between local and international expertise needs to be emphasized. This can improve the capability in terms of technology upgrades and development that can improve the industry's efficiency.

\section{References}

[1] Adhikary, B. K. 2011. FDI, trade openness, capital formation, and economic growth in Bangladesh: a linkage analysis. International Journal of Business and Management, 6: 16.

[2] Agarwal, S., Yadav, S. P., \& Singh, S. P. 2010. DEA based estimation of the technical efficiency of state transport undertakings in India. Opsearch, 47: 216-230.

[3] Annual National Account Report (GDP) 2005 - 2011. 2012 Putrajaya: Department of Statistic.

[4] Avkiran, N. K. 200). Investigating technical and scale efficiencies of Australian universities through data envelopment analysis. Socio-Economic Planning Sciences, 35: 57-80.

[5] Banker, R. D., Charnes, A., \& Cooper, W. W. 1984. Some models for estimating technical and scale inefficiencies in data envelopment analysis. Management science, 30: 1078-1092.

[6] Boame, A. K. 2004. The technical efficiency of Canadian urban transit systems. Transportation Research Part E: Logistics and Transportation Review, 40: 401-416.

[7] Charnes, A., Cooper, W.W., Rhodes, E. 1978. Measuring the Efficiency of Decision Making Unit. European Journal of Operational Research, Vol. 2, 429-444.

[8] Coelli, T. J., \& Battese, G. E. 1996. Identification of factors which influence the technical inefficiency of Indian farmers. Australian Journal of Agricultural Economics, 40(2), 103-128.

[9] Cooper, W. W., Seiford, L. M., \& Tone, K. 2007. The Basic CCR Model. In Data Envelopment Analysis A Comprehensive Text with Models, Applications, References and DEA-Solver Software. 2nd edition. New York: Springer Science Business Media, Inc.

[10] Cullinane, K., Wang, T. F., Song, D. W., \& Ji, P. 2006. The technical efficiency of container ports: comparing data envelopment analysis and stochastic frontier analysis. Transportation Research Part A: Policy and Practice, 40: 354-374. 
[11] Economic Census 2006. 2007. Putrajaya: Jabatan Perangkaan Malaysia

[12] Economic Census 2011. 2012. Putrajaya: Jabatan Perangkaan Malaysia.

[13] Fahmy-Abdullah, M., Ismail, R., N. Sulaiman, N., \& Talib, B. A. 2017. Technical Efficiency in Transport Manufacturing Firms: Evidence from Malaysia. Asian Academy of Management Journal, 22: 57-77.

[14] Farrell, M. J. 1957. The measurement of productive efficiency. Journal of the Royal Statistical Society. Series A (General), 120: 253-290.

[15] Ismail, R., \& Jajri, I. 2008. Analysis of Technical Efficiency Change, Technology Change, Total Factor Productivity in Transport Equipment Industry in Malaysia. Sains Humanika, 49.

[16] Jarboui, S. A. M. I., Pascal, F., \& Younes, B. 2013. Public road transport efficiency: a stochastic frontier analysis. Journal of Transportation Systems Engineering and Information Technology, 13: 64-71.

[17] Khalifah, N. A. 2013. Ownership and technical efficiency in Malaysia's automotive industry: A stochastic frontier production function analysis. The Journal of International Trade \& Economic Development, 22: 509-535.

[18] Kim, S., Lim, H., \& Park, D. 2007. The effect of imports and exports on total factor productivity in Korea. Research Institute of Economy, Trade and Industry Discussion Paper Series, (07-E).

[19] Mahadevan, R. 2004. The economics of productivity in Asia and Australia. Edward Elgar Publishing.

[20] Mankiw, N. G., Phelps, E. S., \& Romer, P. M. 1995. The growth of nations. Brookings papers on economic activity, 1995, pp: 275-326.

[21] MITI. 2013. National Automotive Policy 2013. Ministry of International Trade and Industry.

[22] National Automotive Policy. 2014. Ministry of International Trade and Industry.

[23] Nunamaker, T. R. (1985). Using data envelopment analysis to measure the efficiency of non-profit organizations: A critical evaluation. Managerial and decision Economics, 6(1), 50-58.

[24] Productivity Report 2012 and 2013. Produktivitas Nasional Corporation, Petaling Jaya: Kuala Lumpur.

[25] Research logistics quarterly, 9: 181-186.

[26] Sun, X., Lv, X., \& Li, L. 2015. Sufficient and Comprehensive Measurement of Automobile Manufacturing Industry Performance Applying Bi-objective Super-efficiency DEA.

[27] Yu, M. M., \& Fan, C. K. 2009. Measuring the performance of multimode bus transit: A mixed structure network DEA model. Transportation Research Part E: Logistics and Transportation Review, 43: 501-515. 